\title{
PRODUÇÃO DE CARTILHA "ESCORPIÃO, QUE BICHO É ESSE?": UM RECURSO PARA O ENSINO NA EDUCAÇÃO EM SAÚDE NAS AULAS DE CIÊNCIAS
}

\author{
Apresentação: Pôster \\ Jailson Rodrigues de Oliveira ${ }^{1}$; Kelly do Nascimento Melo $^{2}$; Cristiane Maria da Conceição ${ }^{3}$; \\ Ricardo Ferreira das Neves ${ }^{4}$; Jeanne Claine de Albuquerque Modesto ${ }^{5}$
}

\section{Introdução}

Animais peçonhentos possuem sistema especializado para inocular substâncias tóxicas, cujo veneno é produzido por glândulas especializadas. O escorpião pertence ao filo Arthropoda e constitui a Classe Arachnida e inserido na ordem Scorpione. Esses animais ganham destaque por seu importante papel ecológico e pelos casos de acidentes envolvidos. (CARDOSO et al., 2009).

A Secretaria Estadual de Saúde (SES) apontou que entre os anos de 2009 a 2013, no Estado de Pernambuco, foram registrados 38.188 casos de acidentes com animais peçonhentos, sendo $77,2 \%$ por escorpiões. (BRASIL, 2015). Entre janeiro a agosto deste ano foram registradas 645 ocorrências pelo Centro de Assistência Toxicológica de Pernambuco (CEATOX-PE), referência no Estado para esses casos. (PERNAMBUCO, 2016).

O aparecimento de escorpiões é frequente em épocas quentes e úmidas do ano, nisso os índices de acidentes foram bastante expressivos, cuja informação a população é um elemento promissor para evitar problemas à saúde. Contudo, socialmente ainda se percebe que muitos indivíduos detêm informações errôneas ou deturpadas a visão científica.

Nesse sentido, a escola representa um espaço que deve oportunizar e instigar a reflexão do sujeito, desmistificar ideias do senso comum e possibilitar a mudança conceitual. Para tanto, esse trabalho objetivou produzir uma cartilha para o ensino sobre escorpiões, para estudantes do Ensino Fundamental. A confecção de uma cartilha pode colaborar com a desmistificação sobre esses animais e oportunizar aos alunos melhor compreensão sobre os escorpiões, colaborando com a minimização de acidentes e o equilíbrio ecológico.

\footnotetext{
1 - Graduando em Ciências Biológicas na Universidade Federal de Pernambuco, UFPE/CAV, jailsonr16@ hotmail.com.

2 - Graduanda em Ciências Biológicas na Universidade Federal de Pernambuco UFPE/CAV, ellyk_@ hotmail.com.

3 - Graduada em Ciências Biológicas na Universidade Federal de Pernambuco UFPE/CAV, cr.is.x2@ hotmail.com.

4 - Professor da Universidade Federal de Pernambuco, UFPE/CAV, rico.neves2010@ gmail.com.

5 - Professora da Universidade Federal de Pernambuco, UFPE/CAV, clainealbuquerque@ hotmail.com.
} 


\section{Fundamentação Teórica}

Os animais peçonhentos são aqueles que possuem um aparato inoculador de substâncias tóxicas produzidas diretamente por glândulas especializadas, injetando o "veneno" em suas presas por meio de um mecanismo de defesa ou para alimentação. (CARDOSO et al., 2009). Os acidentes causados por animais peçonhentos representam um problema de saúde pública em países tropicais e subtropicais, atingindo principalmente crianças e idosos. Dos acidentes causados por animais peçonhentos de importância médica, o escorpionismo ganhou destaque devido ao seu elevado índice de ocorrência e seu potencial de letalidade.

No Brasil, diversas espécies de escorpiões podem provocar acidentes, sendo estas pertencentes principalmente ao gênero Tityus. Destacando-se as espécies que podem levar o indivíduo a morte, temos: Tityus serrulatus, Tityus bahiensis e Tityus stigmurus. (ALBUQUERQUE et al., 2009). As espécies da Família Buthidae cujo Gênero Tityus representa $60 \%$ do total de escorpiões existentes na fauna brasileira, incluindo os de importância médica. (BRASIL, 2009). Em Pernambuco, a Secretaria Estadual de Saúde, registrou 645 casos de escorpionismo apenas no primeiro semestre de 2016. (PERNAMBUCO, 2016).

Nessa perspectiva, a melhoria da saúde pública está atrelada ao processo educacional do cidadão, sendo a educação um elemento importante no combate à pobreza, à desigualdade e a exclusão social. Assim, promover um debate da educação e da saúde nas escolas é a maneira de formar cidadãos reflexivos cientes das consequências de seus atos em relação ao ambiente e seu papel na sociedade. (RAMOS et al., 2012).

Para tanto, Harmonia (2016), aponta que o uso de materiais paradidáticos pode representar um diferencial na aprendizagem do aluno, como exemplo a cartilha. A cartilha representa um recurso pedagógico que informa e fornece uma base de conhecimentos sobre qualquer assunto em uma roupagem menos formal, e, portanto, mais familiar aos alunos. Permite ainda apresentar o tema de forma resumida, ilustrativa e com uma linguagem acessível aos diferentes públicos.

A utilização dessa cartilha como material pedagógico tem como motivação principal a sensibilização dos alunos da Educação Básica sobre as causas de escorpionismo, apresentando os escorpiões de importância médica, sua ecologia e as espécies que mais causam acidentes no estado de Pernambuco.

\section{Metodologia}

Inicialmente foi aplicado um questionário de forma qualitativa para alunos do $7^{\circ}$ Ano do Ensino Fundamental numa escola pública, localizada em Vitória de Santo Antão-PE. O processo foi realizado durante o estágio curricular obrigatório, visando captar os conhecimentos prévios dos alunos a respeito do escorpionismo e a partir dessas informações, elaborar a cartilha. Para isso, 
utilizou-se um questionário objetivo, cujas perguntas versavam sobre as características morfológicas e biológicas dos escorpiões e os cuidados quanto à picada desses animais. A partir disso, seguiu-se a elaboração da cartilha.

A cartilha intitulada "Escorpião: que bicho é esse?" possui 20 páginas, sendo o público alvo os alunos da Educação Básica, especificamente os do $7^{\circ}$ Ano do Ensino Fundamental, por apresentarem esse conteúdo no livro didático da disciplina de ciências. Nela, observa-se o habitat, a reprodução, a ecologia, os sintomas e as espécies de importância médica, com destaque para aquelas que causam acidentes em Pernambuco. A cartilha possui uma linguagem acessível e uso de imagens, uso de balões de conversa entre o escorpião e o leitor. A produção foi estruturada no computador pelo programa Microsoft Word e impressa em folha A4 comum. O passo a passo para a confecção da cartilha é detalhado a seguir:

1. Capa - Na confecção da capa foi utilizada folha em EVA (papel emborrachado), sendo desenhado um formato de um escorpião no tamanho de $40 \mathrm{~cm}$ em folha EVA com lápis hidrocor e depois cortado com uma tesoura. (figura 1).

Figura 1: Capa da cartilha: “escorpião: que bicho é esse?”. Fonte: Própria

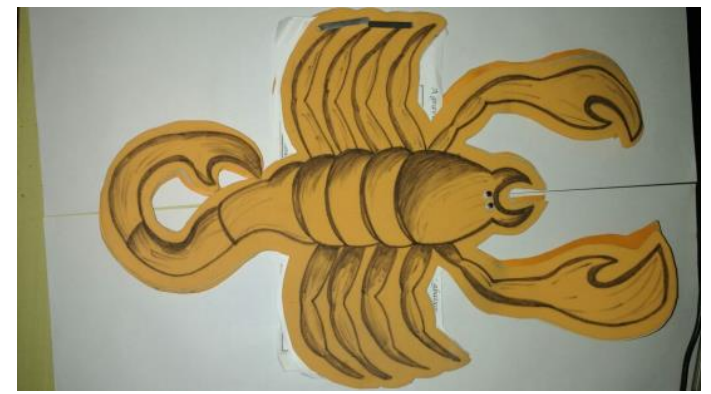

2. Corpo da cartilha (páginas) - Após a confecção da capa, as páginas foram impressas em alta qualidade, em folha de papel A4 e cortadas no formato do corpo do escorpião e em seguida furadas usando um perfurador de papel e as folhas prendidas usando um grampo trilho. (figura 2).

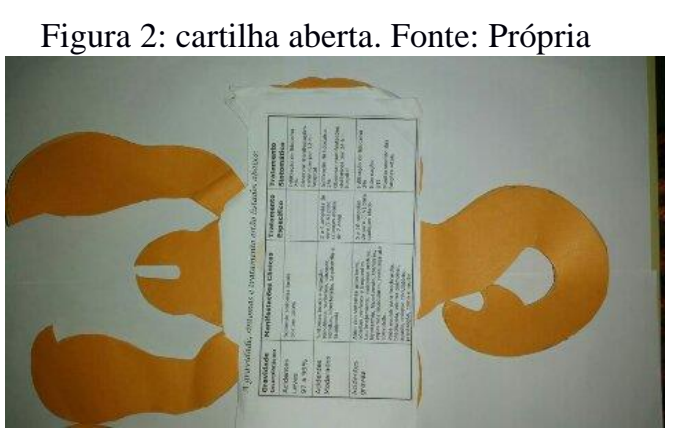

Na figura acima, pode-se observar alguns recortes em destaque da cartilha: "Escorpião: que bicho é esse?". Nas figuras a seguir, observam-se alguns momentos da cartilha, com presença de espécies endêmicas em Pernambuco e um pequeno diálogo entre os escorpiões, permitindo uma compreensão sobre o animal de forma mais lúdica. 
Figura 3: Espécie Tityus stigmurus. Fonte: Laboratório de Fisiologia e Farmacologia Vitória - UFPE/CAV.

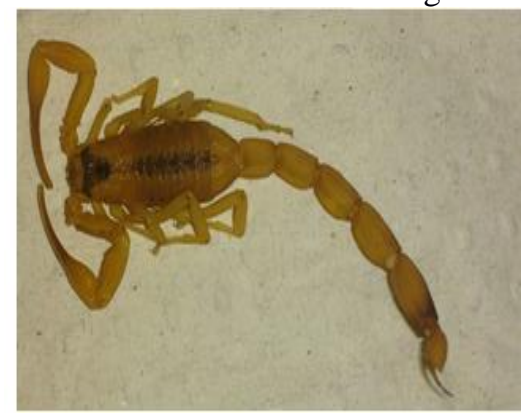

Figura 4: Diálogo entre escorpiões. Fonte: Laboratório de Fisiologia e Farmacologia Vitória - UFPE/CAV.

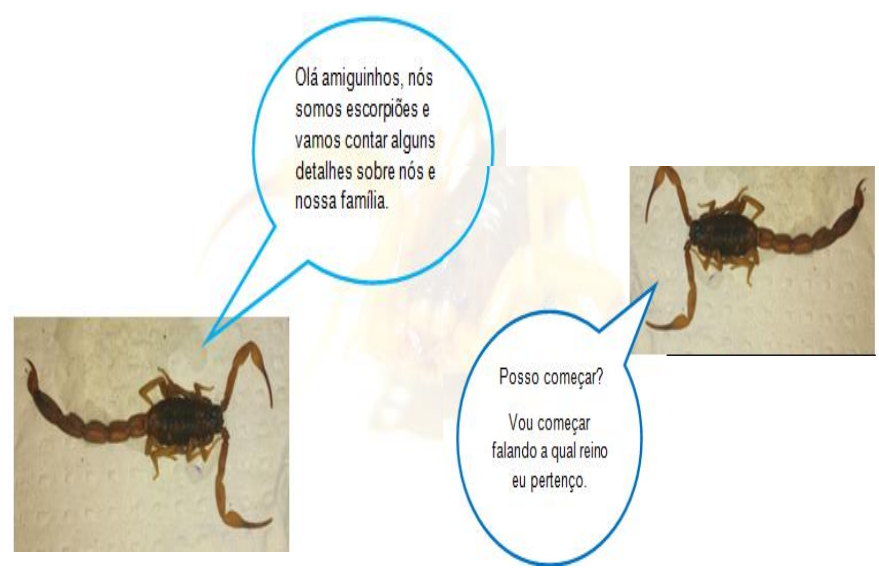

Após a produção, informou-se a professora supervisora de estágio e aos alunos do $7^{\circ}$ Ano da disciplina de Ciências, que a cartilha ficaria na escola disponível a todos os estudantes e aos professores na biblioteca escolar.

\section{Resultados e Discussões}

Cabe aqui ressaltar que, sobre o questionário utilizado para nortear a produção da cartilha. Após a análise, verificou-se que a maioria dos alunos apresentavam dificuldades no entendimento do conteúdo, cujos alunos detinham informações confusas e lacunas conceituais, quanto à compreensão sobre animais venenos e peçonhentos, importância ecológica e prevenção das espécies.

Essas dificuldades verificadas nas concepções dos alunos, também são pontuadas nas discussões de Cardoso et al. (2009), considerando que existe certa confusão pelos estudantes quanto ao conceito de animais peçonhentos e venenosos. Também, que o pouco conhecimento sobre a importância e cuidados com essas espécies, pode colaborar com uma depreciação do animal ou relacioná-los apenas como aspectos negativos, como seres prejudiciais à vida.

Por fim, após a entrega da cartilha, os alunos se debruçaram sobre o material, observando e discutindo sobre o que foi produzido. Dessa forma, o processo de ensino-aprendizagem se tornou bastante significativo, e a aula bem diferente, saindo de um contexto muita vezes estático, para um ambiente mais lúdico, atrativo e prazeroso, a partir da leitura e da visualização de imagens. 


\section{Conclusões}

O questionário possibilitou identificar as dificuldades dos alunos sobre o tema escorpião, cuja situação oportunizou a produção da cartilha, esta de simples e elaboração, colaborando com a desmistificação de ideias do senso comum.

Um recurso como à cartilha pode representar uma ferramenta de ensino e de aprendizagem eficaz na educação em saúde, podendo ser consultada a qualquer momento na escola e utilizada pelos professores em suas aulas.

\section{Referências}

ALBUQUERQUE, C. M. R. et al. Escorpionismo por Tityus pusillus Pocock, 1893 (Scorpiones; Buthidae) no Estado de Pernambuco. Revista da Sociedade Brasileira de Medicina Tropical, Pernambuco, v. 42, n. 2, p.206-208, mar. 2009.

BRASIL. Manual de Controle de Escorpiões. Secretária Estadual de Saúde. (Série B. Textos Básicos de Saúde). Brasília: Editora Ms, 2009.

BRASIL. Vigilância e Controle de Acidentes por animais peçonhentos. Secretária Estadual de Saúde. 2015. Disponível em: <http://portal.saude.pe.gov.br/programa/secretaria-executiva-devigilancia-em-saude/vigilancia-e-controle-de-acidentes-por-animais>. Acesso em: 27 out. 2016.

CARDOSO, J. L. C et al. Animais peçonhentos do Brasil. Biologia, Clínica e Terapêutica dos acidentes. $2^{\text {a }}$ Ed. Brasil: Sarvier, 2009.

HARMONIA, Eco. Cartilhas pela Natureza. Disponível em: <http://www.ecoharmonia.com/2011/11/cartilhas-pela-natureza.html>. Acesso em: 01 out. 2016.

PERNAMBUCO. Centro de Assistência Toxicológica de Pernambuco (Ceatox/PE) capacita sobre intoxicações e acidentes com animais peçonhentos. Disponível em: <http://www.pe.gov.br/blog/2016/09/19/8203-ceatox-capacita-sobre-intoxicacoes-e-acidentes-comanimais-peconhentos/>. Acesso em: 01 out. 2016.

RAMOS, E. L. P. et al. Uma Abordagem Lúdica dos Animais Peçonhentos no Ensino Fundamental. Em Extensão. Uberlândia, v. 11, n. 2, p.45-53, jul. 2012. 